This item was submitted to Loughborough's Research Repository by the author.

Items in Figshare are protected by copyright, with all rights reserved, unless otherwise indicated.

\title{
Cycle-to-cycle variation analysis of two-colour PLIF temperature measurements calibrated with laser induced grating spectroscopy in a firing GDI engine
}

\section{PLEASE CITE THE PUBLISHED VERSION}

https://doi.org/10.4271/2019-01-0722

PUBLISHER

SAE International

\section{VERSION}

AM (Accepted Manuscript)

\section{PUBLISHER STATEMENT}

This paper was accepted for publication in the journal SAE International Journal of Advances and Current Practices in Mobility and the definitive published version is available at https://doi.org/10.4271/2019-01-0722.

\section{LICENCE}

CC BY-NC-ND 4.0

\section{REPOSITORY RECORD}

Willman, Christopher, Richard Stone, Martin Davy, Benjamin AO Williams, Paul Ewart, Li Shen, David LS Hung, Mengqi Liu, and Joe Camm. 2019. "Cycle-to-cycle Variation Analysis of Two-colour PLIF Temperature Measurements Calibrated with Laser Induced Grating Spectroscopy in a Firing GDI Engine". Loughborough University. https://hdl.handle.net/2134/12252917.v1. 


\title{
Cycle-to-Cycle Variation Analysis of Two-Colour PLIF Temperature Measurements Calibrated with Laser Induced Grating Spectroscopy in a Firing GDI Engine
}

\author{
Christopher Willman, Richard Stone, Martin Davy, Benjamin A. O. Williams and Paul Ewart \\ University of Oxford \\ Li Shen, David L. S. Hung and Mengqi Liu
University of Michigan - Shanghai Jiao Tong University Joint Institute, Shanghai Jiao Tong University \\ Joseph Camm \\ Loughborough University
}

\begin{abstract}
In-cylinder temperatures and their cyclic variations strongly influence many aspects of internal combustion engine operation, from chemical reaction rates determining the production of NOx and particulate matter to the tendency for auto-ignition leading to knock in spark ignition engines. Spatially resolved measurements of temperature can provide insights into such processes and enable validation of Computational Fluid Dynamics simulations used to model engine performance and guide engine design.
\end{abstract}

This work uses a combination of Two-Colour Planar Laser Induced Fluorescence (TC-PLIF) and Laser Induced Grating Spectroscopy (LIGS) to measure the in-cylinder temperature distributions of a firing optically accessible spark ignition engine. TC-PLIF performs 2-D temperature measurements using fluorescence emission in two different wavelength bands but requires calibration under conditions of known temperature, pressure and composition. Here the TC-PLIF technique is calibrated in-situ using high precision $(<1 \%)$ LIGS point measurements.

Temperature distributions were recorded during the compression stroke for fired operation with Direct Injection and with Plenum Fuel Injection of three two-component fuels containing toluene and isooctane. Temperature inhomogeneity was observed for all fuels and injection strategies, with $\mathrm{mm}$-scale regions having temperatures up to $10 \%$ higher than the local environment. Charge cooling of $3 \%$ due to direct injection was resolved.

Proper Orthogonal Decomposition (POD) was used to quantify the cycle-to-cycle variation of the temperature data. Low-order POD modes featured most of the cyclic variation in temperature and the corresponding mode coefficients were used to investigate correlations with combustion analysis, fuel injection strategies and toluene content of the fuel. Additionally, the low-order POD mode coefficients provided an opportunity to identify cycles containing local hotspots or outlier measurements.

\section{Introduction}

Fuel economy and emissions are key targets in engine design, leading to the current trend of high compression ratios, downsizing and boosting aimed at improving efficiency in spark ignition engines $[1,2]$.

Page 1 of 14
The higher pressures and temperatures involved in such operating conditions lead to an increased tendency for auto-ignition of the endgas to occur before the spark-induced flame propagates through the entire cylinder, resulting in engine knock and limiting the optimization of spark ignition engine operation $[3,4]$. To protect the engine components from damage caused by knocking combustion, aside from using fuels with a high octane index which are more resistant to auto-ignition [5], various methods are typically employed to reduce the temperature and pressure of the end gas including: retarding the spark timing [6], utilizing the charge cooling effect of direct injection [7], reducing the effective compression ratio through variable valve operation [8], or introducing exhaust gas recirculation [9].

In addition to the compromises involved in avoiding knock during idealized engine operation, the cyclic variability of engine combustion results in engine designs incorporating a safety margin with an associated further reduction in efficiency. Improved knowledge of the cycle-to-cycle variations can provide valuable insights, with the aim of designing engines to be reliably operated closer to knock-limited conditions.

Optical techniques for spatially and temporally resolved in-cylinder temperature measurements provide a non-intrusive opportunity to investigate the cyclic variations in the temperature distributions across the cylinder [10-13]. Regions of increased local temperature, of the order of $10 \mathrm{~K}$ higher than the bulk gas, may have the potential to trigger auto-ignition events when running close to knocking conditions $[14,15]$, and localized hot spots with temperatures 5\% higher than the bulk gas have been found to be correlated with knock [16].

In this work, cycle-to-cycle variations of the in-cylinder temperature field during fired operation of a spark ignition engine are analysed using Proper Orthogonal Decomposition (POD). The novel combination of the two optical diagnostic techniques: Two-colour Planar Laser Induced Fluorescence (TC-PLIF) and Laser Induced Grating Spectroscopy (LIGS) introduced previously [17] provides insitu calibrated, spatially resolved temperature measurements of the unburned gas during the compression stroke.

\section{Optical diagnostics}

Planar Laser-Induced Fluorescence (PLIF) using tracer molecules added to or present in fuel is a widely used technique to perform in- 
cylinder temperature measurements across a plane [18]. The requirement common to tracer based PLIF techniques which rely on the temperature dependence of either the emission spectrum [19-23] or absorption spectrum [24-26] of the tracer species is the need to calibrate the relationship between the experimental signals and temperature. While toluene, acetone and 3-pentanone have been wellstudied in conditions relevant to IC engines [27-31] accurate temperature measurements require the chosen PLIF technique to be calibrated empirically.

This is typically achieved either by comparison to measurements obtained under known conditions of temperature, composition and pressure $[21,32,33]$ or by calibrating a region of the PLIF images to the polytropic compression temperature [23]. Any differences between the calibration and measurement environments or uncertainties in the assumptions of the calibration will translate into uncertainty in the derived temperatures. This is of particular importance to fired engine measurements where the presence of hot combustion products in the residual exhaust gas complicates the compositional assumptions of the calibration.

Performing simultaneous measurements with an independent thermometry technique, at a location within the PLIF measurement plane, allows the PLIF technique to be calibrated in-situ under conditions identical to the measurement by definition. In-cylinder conditions are often varied throughout a set of experimental runs. Simultaneous measurements with both techniques provide an opportunity for updating the calibration for each condition and for independently validating features within temperature fields identified by PLIF.

Selection of LIGS as the optical technique to provide in-situ calibration was based on the requirements of a temporally and spatially resolved measurement while maximizing the robustness and precision of the temperature measurements used for calibration.

Tunable Diode Laser Absorption Spectroscopy (TDLAS) can be readily applied to target typical combustion products $\left(\mathrm{H}_{2} \mathrm{O}, \mathrm{CO}_{2}, \mathrm{CO}\right.$, $\mathrm{NO}, \mathrm{OH}$ ) [34], and is suited for in-cylinder thermometry [35]. However as a path-integrated technique, TDLAS will provide a nonlinearly averaged temperature along the beam path, rather than the temperature at a specific location within the TC-PLIF measurement plane as required for calibration.

The rotational variant of Coherent Anti-Stokes Raman Scattering (CARS) is a four wave mixing technique using the rotational energy levels of the target species to provide measurements suited to incylinder thermometry [36]. Fitting a theoretical spectrum to the spectrally resolved signal beam is affected by intensity fluctuations in spectral intensity of the broadband Stokes beam, and in scattered and background light resulting in single-shot precisions of a few percent [37-42].

Laser-Induced Grating Spectroscopy (LIGS) [43], provides a temperature measurement at a point and is capable of very high precisions in the range $0.1-1 \%$ [44]. Key to its suitability for engine applications is that temperature is derived from the signal's oscillation frequency, resulting in high precision and robustness against signal intensity fluctuations, and that the precision of the measurement improves with increasing pressure. LIGS may be performed using non-resonant pump beams to generate an electrostrictive grating $[45,46]$, enabling tracer-free measurements in air [47] and under optimal conditions achieves an accuracy of $<1 \%$ with a precision of $0.5 \%$ [48]. In this work, the ready availability of toluene as a component of the fuel enables the use of resonant absorption of the pump beams to generate a thermal grating [49-52].

Page 2 of 14
For high pressures (40 bar) and low temperatures ( $<400 \mathrm{~K})$ this has been shown to achieve an accuracy of $0.42 \%$ with a precision of $0.16 \%[53]$.

\section{Two-Colour Planar Laser-Induced Fluorescence (TC- PLIF)}

For one-colour detection involving a single excitation sheet and camera, the detected PLIF fluorescence signal, $S$, in photons per pixel is given by,

$$
S=\frac{E}{h v} V_{p} n_{t r} \sigma \phi \frac{\Omega}{4 \pi} \eta_{o p t}
$$

which is dependent on: the excitation laser sheet's energy per volume via its fluence, $E$, frequency, $v$, and Planck's constant, $h$; the tracer species' number density, $n_{\mathrm{tr}}$, absorption cross-section, $\sigma$, and fluorescence quantum yield, $\phi$; and the imaging geometry via the excitation volume imaged onto one pixel, $V_{\mathrm{p}}$, the solid angle subtended by the collection optics, $\Omega$, and the transmission efficiency of the collection optics, $\eta_{\mathrm{opt}}$ [ $[26,54]$.

The laser sheet energy, absorption cross section and tracer number density may all vary as a function of position within the measurement plane. These parameters must therefore be corrected for in derivation of temperature from one-colour detection PLIF images.

Two-Colour detection PLIF (TC-PLIF) utilises the temperature dependence of the tracer species' emission spectrum to provide a measurement independent of these potentially unknown experimental parameters. This is achieved by imaging the fluorescence emission in two spectral windows, $\Delta \lambda_{1}$ and $\Delta \lambda_{2}$, and forming a signal ratio to cancel identical contributions to each signal, $S_{1}$ and $S_{2}$,

$$
\frac{S_{1}}{S_{2}}=C \frac{\phi\left(\Delta \lambda_{1}, T\right)}{\phi\left(\Delta \lambda_{2}, T\right)}
$$

where $C$ is a calibration factor and $T$ is temperature. As compared and experimentally verified in [19], under well characterised conditions one-colour detection PLIF provides higher sensitivity due to the larger absolute change in $S$ compared to the ratio $S_{1} / S_{2}$ and higher precision due to the low signal intensities of TC-PLIF as a direct result of discarding fluorescence emission outside of the two spectral windows. However, for fired engine experiments the independence of spatial variations in composition of the TC-PLIF technique is invaluable and hence TC-PLIF is used in this work.

Two-line excitation PLIF follows a similar methodology to the signal ratio of TC-PLIF by using two sequential laser sheets to excite the absorption spectrum at different wavelengths. This results in higher signal intensities than TC-PLIF but requires two excitation lasers and retains the dependence on laser sheet energy and absorption crosssection as a function of position. Accounting for such effects via the use of beam homogenizers to minimize spatial variations in laser sheet intensity [55] and careful calibration over wide pressure, temperature and composition ranges can result in high quality temperature measurements for fired engine operation [33].

\section{Laser Induced Grating Spectroscopy (LIGS)}

In-depth theoretical discussions of LIGS grating formation [49-52] and its application for measurements in combustion relevant environments including flames [56-59], IC engines [44, 60], flashboiling sprays [61], shock tubes [62], and rapid compression 
machines [63] are available in the literature. A brief description of the LIGS technique is provided here for the convenience of the reader.

LIGS thermometry directly measures the speed of sound in a gas, which can be used to derive temperature when combined with an equation of state and knowledge of the local gas composition.

A pair of pulsed pump beams are crossed at the measurement location to form an interference pattern of bright and dark fringes with a fixed spacing, $\Lambda$. This leads to the creation of an oscillating density perturbation, the LIGS grating, formed from a combination of a 'thermal' component and an 'acoustic' component.

Resonant absorption of light by tracer molecules within the 'bright' planes perturbs the local temperature of the bulk gas via collisional quenching. This leads to the formation of a periodic 'thermal' density perturbation with low densities within the 'bright' planes.

The rapid deposition of energy by the short duration pump laser pulses $(<10 \mathrm{~ns})$ leads to pressure rises within the 'bright' planes. The resulting acoustic waves travel across the thermal grating at the local sound speed, $c_{\mathrm{s}}$, modifying the periodic density perturbation with an oscillation frequency, $f_{\text {osc }}$, given by,

$$
f_{\text {osc }}=\frac{c_{s}}{\Lambda}
$$

A probe beam of wavelength $\lambda_{\text {probe }}$ incident on the grating at the Bragg-scattering angle, $\phi_{B}$,

$$
\phi_{B}=\sin ^{-1}\left(\frac{\lambda_{\text {probe }}}{2 \Lambda}\right)
$$

will be coherently scattered with an efficiency depending on the magnitude of the LIGS grating's density perturbation, and is used to readout the temporal evolution of the grating. The intensity of this coherent signal beam decays over time due to diffusion of the gas molecules, and viscous damping leading to the dissipation of the thermal grating and acoustic wave amplitudes respectively [Figure 1].

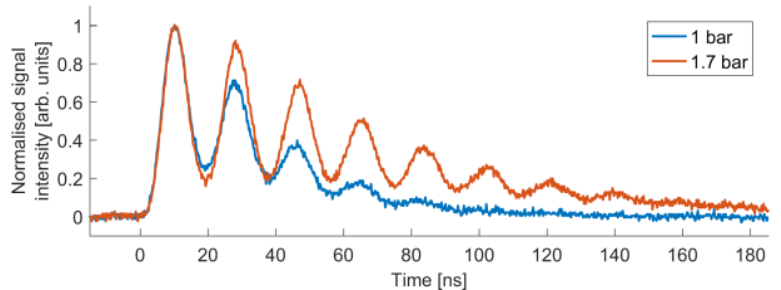

Figure 1 Example single-shot LIGS signals recorded in a static cell displaying the characteristic oscillations from which temperature is derived, along with the decay of the signal and damping of the oscillations over time. The increase in signal lifetime with increasing pressure enables the oscillation frequency and hence temperature to be determined with higher precision.

For the case of an ideal gas, the sound speed $c_{\mathrm{s}}$

$$
c_{S}=\sqrt{\frac{\gamma k_{B} T}{m}}
$$

is related to temperature, $T$, by Boltzmann's constant, $k_{\mathrm{B}}$, and the local composition of the gas encoded by the mean molecular mass, $m$, and the ratio of specific heats at constant pressure to constant volume, $\gamma$. The local temperature may then be derived from the measurement of the oscillation frequency via Fourier transform of the signal,

Page 3 of 14

$$
T=\frac{m \Lambda^{2}}{\gamma k_{B}} f_{o s c}^{2}
$$

Under the conditions of this work, the dominant contribution to the uncertainty of the LIGS temperature measurements of $1.3 \%$ is due to the upper limit of $23 \%$ variability in local fuel concentration determined in previous work [64] via the variation in the ratio of $m / \gamma$.

\section{Proper Orthogonal Decomposition (POD)}

Proper orthogonal decomposition (POD) was introduced by Lumley [65] into the field of fluid mechanics as an alternative method to analyse turbulent flows. The technique was first used to identify organised bulk motion (also known as coherent structure) and to obtain lower-dimensional models of simple-geometry classical turbulent flow fields, such as flows in a channel [66] and over a flat plate [67], before its subsequent implementation on engine incylinder flow fields in which the geometry is much more complicated. The coherent structures of in-cylinder flows are used to explain larger scale flow variations between engine cycles (i.e., cycle-to-cycle variation) $[68,69]$, as opposed to the remaining flow structures (residues) which are regarded as either smaller scale turbulence within the flow fields $[70,71]$, or noise present in experimental measurements [72].

In addition to vectorial data, POD can also be implemented on scalar fields that are relevant to engine in-cylinder conditions. Bizon et al. [73] applied POD to combustion flame luminosity data and identified that the fluctuations are mostly concentrated on the border and the two ends of the jet flames. Chen et al. [74] examined fuel spray patterns using POD and found that the patterns are deflected by intake charge motion. The studies on cyclic variation of in-cylinder temperature data, however, are limited.

Proper orthogonal decomposition is a variant of principle component analysis (PCA) [75], and thus has its roots in the fields of optimization and multivariate statistics. When an ensemble of samples is considered as a multivariate data set (with the scalar or vector data on individual grid points being the random variables), the result of the POD analysis of the ensemble is a series of patterns (known as POD modes) that successively maximize the sample variance. It is on the basis of this property of optimality that the first several (lower) POD modes are identified as the coherent structures dominating the fields within the ensemble.

\section{Apparatus and experimental procedure}

\section{Optical engine}

The DISI single-cylinder optical engine used in this work has a combustion chamber based on the Jaguar Land Rover AJ133 engine [76]. Two fuel injectors, one mounted centrally in the pent-roof of the cylinder and one mounted in the far end of the intake plenum from the intake ports, allowed for both Direct Injection (GDI) and Plenum Fuel Injection (PFI) injection strategies to be investigated. Three twocomponent fuels were investigated with varying proportions of toluene, the target species for the TC-PLIF and LIGS techniques, and iso-octane, a non-fluorescing base component. The compositions of the three fuels and the nomenclature used to refer the combination of fuel and injection strategy throughout this paper are detailed in Table 1. Injection durations were selected to ensure stoichiometric fired operation. 


\begin{tabular}{|l|l|l|l|l|}
\cline { 3 - 5 } \multicolumn{2}{|c|}{} & \multicolumn{3}{c|}{ Fuel composition (\% by volume) } \\
\cline { 3 - 5 } & $\begin{array}{l}10 \% \text { toluene } \\
90 \% \text { iso-octane }\end{array}$ & $\begin{array}{l}30 \% \text { toluene } \\
70 \% \text { iso-octane }\end{array}$ & $\begin{array}{l}50 \% \text { toluene } \\
50 \% \text { iso-octane }\end{array}$ \\
\hline $\begin{array}{l}\text { Injection } \\
\text { strategy }\end{array}$ & PFI & PFI-10 & PFI-30 & PFI-50 \\
\cline { 2 - 5 } & GDI & GDI-10 & GDI-30 & GDI-50 \\
\hline
\end{tabular}

Optical access is provided by four $16 \mathrm{~mm}$ clear aperture windows equally spaced around the top of the cylinder and a $60 \mathrm{~mm}$ diameter piston crown window in combination with a 45-degree mirror within a Bowditch extended piston.

Data acquisition and timing of injection and ignition events were controlled using a LabVIEW program. Synchronisation of the laser and camera triggers for the PLIF and LIGS techniques was achieved using a BNC-575 pulse generator. Intake air temperature and flow rate, along with coolant temperature were controlled to the values in Table 2. For fired operation the presence of exhaust residuals, approximately $13 \%$, was defined by the valve timing as exhaust gas recirculation was not implemented.

Table 2 Engine specifications and operating conditions

\begin{tabular}{|l|l|}
\hline Bore $\times$ Stroke & $89 \times 90.3 \mathrm{~mm}$ \\
\hline Displacement & $562 \mathrm{~cm}^{3}$ \\
\hline Valves per Cylinder & 2 intake, 2 exhaust \\
\hline Compression Ratio & 11.1 \\
\hline Fuel Pressure (GDI) & $150 \mathrm{bar}$ \\
\hline Injector (GDI) & Bosch Multi-hole Nozzle \\
\hline Fuel Pressure (PFI) & $3.5 \mathrm{bar}$ \\
\hline Valve Timing $\left({ }^{\circ} \mathrm{CA}\right.$ aTDC) & $\begin{array}{l}\text { IVO 34, IVC 242, } \\
\text { EVO } 475, \text { EVC 5 }\end{array}$ \\
\hline Start of Injection (PFI and GDI) & $280^{\circ} \mathrm{bTDC}$ \\
\hline Start of Ignition & $35^{\circ} \mathrm{bTDC}$ \\
\hline Engine speed & $1185 \mathrm{rpm}$ \\
\hline Intake air pressure & $0.4 \mathrm{bar}$ \\
\hline Intake air flow rate & $1.78 \pm 0.02 \mathrm{~L} / \mathrm{s}$ \\
\hline Intake air temperature & $313 \mathrm{~K}$ \\
\hline Coolant temperature & $293 \mathrm{~K}$ \\
\hline Lambda & $1.00 \pm 0.01$ \\
\hline
\end{tabular}

In-cylinder pressure measurements were recorded by a water-cooled Kistler $6041 \mathrm{~A}$ pressure transducer at a resolution of $1{ }^{\circ} \mathrm{CA}$. These were recorded using a National Instruments PCI-M10-16E-1 card. The measurements were pegged to the value of the inlet manifold pressure during a suitable point in the intake stroke. Pressure measurements were recorded for around 1000 cycles so that pressure data is available for every cycle, including those when no TC-PLIF measurement was taken.

From the pressure trace, the net IMEP and mass fraction burnt (MFB) profiles are calculated, using the standard Rassweiler and Withrow method, from which combustion duration and timing metrics were found. In this paper, CA10, CA50, CA80 and CA90 are assessed, which are the crank angle for $0-10 \%, 0-50 \%, 0-80 \%$ and $0-90 \%$ of mass fraction burnt, respectively. The value of polytropic index was calculated from the compression stroke pressure trace.
A detailed description of the optical layout of the combination of TCPLIF and LIGS optical diagnostic techniques is available in [17]; a brief summary is also provided here.

The $266 \mathrm{~nm}$ pulsed excitation sheet for the TC-PLIF technique is introduced into the cylinder through the flat piston crown window and illuminates a $1 \mathrm{~mm}$ thick section of the tumble plane containing the cylinder axis [Figure 2], exciting the toluene molecules present in the fuel. The resulting fluorescence emission is imaged through the $16 \mathrm{~mm}$ aperture windows via a dichroic mirror (edge wavelength 310 $\mathrm{nm}$ ) onto a pair of intensified cameras (Princeton Instruments ICCDs: $576 \mathrm{G} / \mathrm{RB}$ and $512 \mathrm{~T})$, with a longpass (>310 $\mathrm{nm})$ and bandpass $(270$ $-290 \mathrm{~nm}$ ) filter respectively to provide the two images of fluorescence from different spectral regions required for TC-PLIF measurement of temperature.

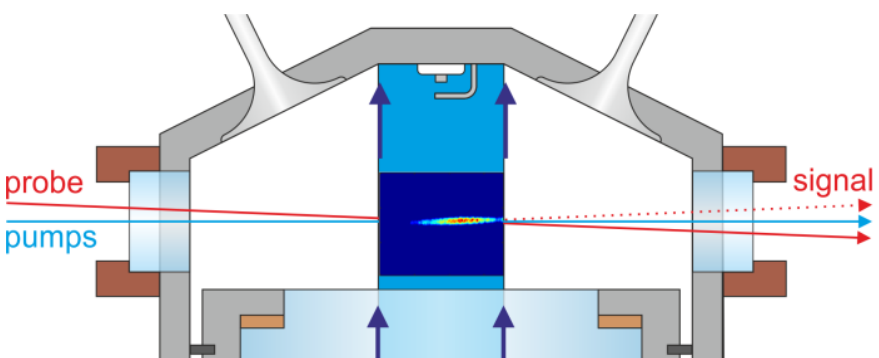

Figure 2 Elevation view of the optical measurement geometry within the central tumble plane. The TC-PLIF measurement region, approximately $9 \mathrm{~mm}$ x $10 \mathrm{~mm}$ and highlighted in dark blue, is located in the centre of the cylinder with the excitation sheet entering from below through the piston crown window via a Bowditch extended piston. The LIGS measurement region, transverse dimensions of $1 \mathrm{~mm}$ and longitudinal dimension of $<10 \mathrm{~mm}$, intersects the TC-PLIF measurement plane as shown by the false-colour image within the TC-PLIF region.

The two pulsed $266 \mathrm{~nm}$ excitation beams and continuous $671 \mathrm{~nm}$ probe beam for the LIGS technique were crossed at an angle of $2.5^{\circ}$ in the centre of the cylinder via the opposing $16 \mathrm{~mm}$ aperture windows on the exhaust and inlet sides of the cylinder. This resulted in the long axis of the LIGS measurement volume $(<10 \mathrm{~mm})$ being aligned within the TC-PLIF measurement plane, with shorter transverse axes of $1 \mathrm{~mm}$ [Figure 2]. The LIGS measurements are subsequently used to provide a calibration at a point within the planar TC-PLIF temperature fields. Each LIGS temperature measurement occurs within $300 \mathrm{~ns}$ of the corresponding TC-PLIF measurement and can be considered simultaneous on the timescale of in-cylinder flows.

The maximum frame rate of the intensified cameras used in this work limited the measurement frequency to approximately $1 \mathrm{~Hz}$, resulting in one temperature measurement for every 10 cycles at $1185 \mathrm{rpm}$. Towards the end of the compression stroke the flat-top piston rises to cover the optical windows at the top of the cylinder restricting the latest possible measurement timing to $50^{\circ} \mathrm{CA}$ bTDC.

\section{Cycle-to-cycle variation analysis methodology}

\section{Spearman's Ranked Correlation Coefficient and Test of Significance}

Given two parameters $x$ and $y$, their Spearman's ranked correlation coefficient (denoted by $R$ ) is defined by [77]: 


$$
R=\frac{\operatorname{Cov}\left(x^{*}, y^{*}\right)}{S D_{x^{*}} \cdot S D_{y^{*}}}
$$

where $\operatorname{Cov}(\cdot, \cdot)$ denotes the covariance, $S D$ refers to standard deviation, $x^{*}$ and $y^{*}$ are the ranks ${ }^{1}$ of $x$ and $y$, respectively. Its value ranges from 0 (no correlation between the two parameters) to 1 (exact correlation).

A two-sided test is implemented to test the null hypothesis of no correlation against the alternative of non-zero correlation [77]. Small $p$ value obtained by the test would reject the null hypothesis, and shows that the two parameters have significant correlation (i.e., $R_{S}$ is significantly far away from zero).

\section{Proper Orthogonal Decomposition}

In this paper, the proper orthogonal decomposition is performed on data sets consisting of $N$ fluctuating temperature fields (denoted by $\widehat{T}_{n}, n=1,2, \ldots, N$ ) that were obtained by centring the original temperature measurements (denoted by $T_{n}$ ) around the spatial average of each cycle:

$$
\widehat{T}_{n}=T_{n}-\frac{1}{L} \cdot \sum_{l=1}^{L} T_{n, l}
$$

where $T_{n, l}$ is the temperature at location $l$ within measurement $n$. Each measurement corresponds to the calibrated pixel-wise signal ratio of two ICCD images, hence each $T_{n}$ contains temperature values, $T_{n, l}$, at $L$ locations under the same engine operation condition (i.e., the same fuel injection strategy and toluene level).

The POD modes and coefficients can be computed by directly performing singular value decomposition (SVD) of the fluctuating temperature fields, in which the procedure is presented in the appendix. Each fluctuating temperature field can therefore be represented by a linear combination of $M$ POD modes (denote $\phi^{(m)}$, $m=1,2, \ldots, M)$ :

$$
\widehat{T}_{n}=\sum_{m=1}^{M} \phi^{(m)} \cdot C_{n}^{(m)}
$$

where $C_{n}^{(m)}$ denotes the mode $m$ coefficient of Cycle $n$. The decomposition has two properties. For one, the POD modes are normalized and orthogonal to each other, i.e., $\phi^{(i)} \cdot \phi^{(j)}=\delta_{i j}$, where $\delta_{i j}$ is the Kronecker delta. For the other, the sum of squared coefficients over cycles is successively maximized, i.e.,

$$
\max \left\{\sum_{n=1}^{N}\left(C_{n}^{(m)}\right)^{2}\right\}
$$

from the first mode to the last (mode $M$ ). Moreover, the SVD process gives ranked singular values $\left(\sigma_{1} \geq \sigma_{2} \geq \cdots \geq \sigma_{M}\right)$, and the squares of them $\left(\sigma_{m}^{2}\right)$ are eigenvalues $\left(\lambda_{m}\right)$ of a covariance matrix $S=\widehat{T} \widehat{T}^{\prime}$, whose eigenvectors are exactly the POD modes. Therefore, the

\footnotetext{
${ }^{1}$ Suppose $x$ has 100 samples, the rank of $x$ is found by sorting $x$, say, from the smallest to the highest. The rank of the smallest value is 1 , and the rank of the highest value is then 100 .
}

eigenvalues quantify the amount of variation captured by each mode, and lower-order POD modes feature the major variation within the temperature field since they have larger eigenvalues.

\section{Relevance Index}

The relevance index [78] quantifies the similarity between two fields $a$ and $b$ :

$$
R I=\frac{a \cdot b}{\|a\| \cdot\|b\|}
$$

where $a \cdot b$ denotes the inner product of any two fields $a$ and $b$, and $\|\cdot\|$ is the $L^{2}$ norm. The fields can either be temperature fields or POD modes. The absolute value of the relevance index (relevance index magnitude) is equal to 1 if the two fields are linear multiples of each other (most similar), and is equal to 0 if the two fields are independent (least similar).

\section{Experimental results}

\section{LIGS and TC-PLIF temperature measurements}

This section firstly presents the in-cylinder temperature fields derived from TC-PLIF measurements, calibrated in-situ using LIGS for fired operation, and discusses the validation of the measured temperature inhomogeneities. Secondly, in-cylinder pressure measurements are used to analyse the combustion variability of each test condition. Finally, Proper Orthogonal Decomposition is used to identify outlier cycles and to investigate correlation between the spatial distribution of optically-measured temperatures and the pressure-derived combustion parameters.

\section{Motored operation}

Simultaneous LIGS and TC-PLIF measurements were performed once every 10 cycles in increments of $10^{\circ} \mathrm{CA}$ from $90^{\circ} \mathrm{CA}$ to $50^{\circ} \mathrm{CA}$ bTDC during the compression stroke. An early injection timing of $280^{\circ} \mathrm{CA}$ bTDC for both GDI and PFI was selected to minimize piston wetting for GDI operation. While tracer homogeneity is not required for the TC-PLIF technique, this condition has previously been shown to produce a spatially homogeneous fuel-air mixture [64] which minimizes the main source of uncertainty of the LIGS technique in this application, the local mixture composition [44]. Image corrections for the TC-PLIF imaging system, including accounting for the dependency of the dichroic mirror's transmission spectrum on incidence angle, were determined at $90^{\circ} \mathrm{CA}$ bTDC under the assumption of a homogenous temperature field in the centre of the cylinder at this condition. For a detailed discussion of image processing for PLIF thermometry, including dichroic filter effects, the reader is referred to [19]. Mean LIGS temperatures from 20 measurements at each crank angle increment were used to provide insitu calibration of the TC-PLIF temperature fields for each dataset.

Initial measurements for motored operation found the temperature fields to be spatially homogeneous with small scale fluctuations of $0.2 \mathrm{~mm}$, matching the size of the 7 pixel FWHM smoothing Gaussian filter applied to the raw images. These fluctuations can be attributed to noise present in the images due to the combination of the low signal intensities in each spectral window characteristic of TC-PLIF and intensifier gain, resulting in a pixel-wise temperature uncertainty of $4 \%$ for PFI-30 operation [Figure 3]. 


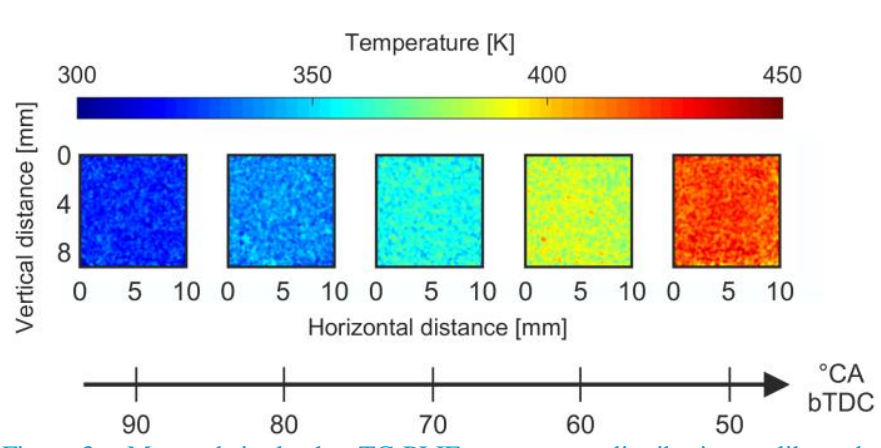

Figure 3 Motored single-shot TC-PLIF temperature distributions calibrated in-situ with LIGS for the PFI-30 fuel condition. Each temperature field is an example taken from a subset of 20 measurements performed from $90^{\circ} \mathrm{CA}$ to $50^{\circ} \mathrm{CA}$ bTDC in increments of $10^{\circ} \mathrm{CA}$.

\section{Fired operation}

Operation of the optical engine under firing conditions for an extended period of time caused the piston rings to overheat and increased the likelihood of damaging the optical windows. It was therefore not practical to allow the engine to reach a stable firing operating condition, as defined by a constant exhaust temperature. In order to minimize the deviation from realistic operating conditions, the engine was not skip-fired. Instead, fired operation was limited to two-minute durations, with each optical measurement set of 100 simultaneous TC-PLIF and LIGS measurements recorded at $1 \mathrm{~Hz}$ after a 20 second initial warmup period, during which the measured lambda value stabilized to $1.00 \pm 0.01$. Between each measurement set, the engine was motored to return to a consistent initial temperature.

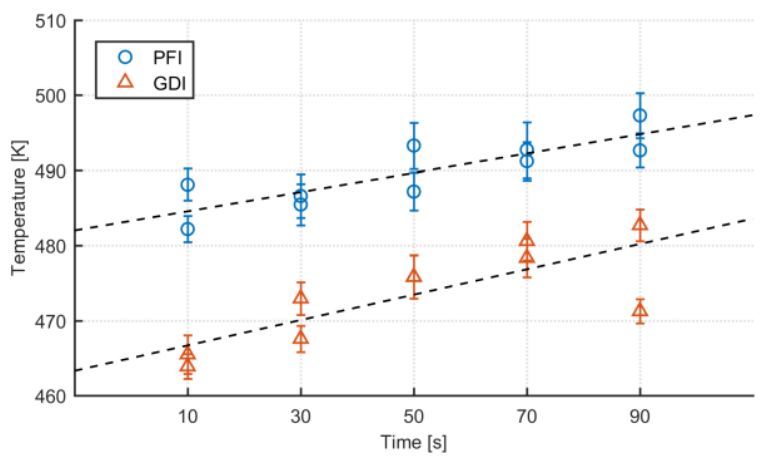

Figure 4 LIGS temperatures measurements at $50^{\circ} \mathrm{CA}$ bTDC for fired operation with PFI-30 and GDI-30, recorded during the 100-second TC-PLIF measurement period. Datasets from two repeats of each injection condition are shown. The 100 measurements of each dataset have been averaged in 5 groups of 20 sequential measurements, with errorbars representing the standard error of the mean.

Figure 4 displays LIGS temperatures recorded during the 100 -second measurement period for fired operation for both PFI-30 and GDI-30 conditions. For both injection strategies the in-cylinder temperatures were found to increase at a rate of $9 \mathrm{~K} \mathrm{~min}^{-1}$ due to heat transfer from combustion events to the cylinder head, walls and piston and subsequently to the incoming charge of the next cycle. This bulk temperature rise must be accounted for in any discussion of temperature trends within a dataset. GDI-30 operation shows a reduction in temperature of $16 \mathrm{~K}$ at $50^{\circ} \mathrm{CA}$ bTDC compared to PFI- 30 due to the charge cooling effect of direct injection of fuel into the cylinder, combined with any differences in combustion behaviour modifying the heat transfer to the fresh charge [Figure 4].

Page 6 of 14

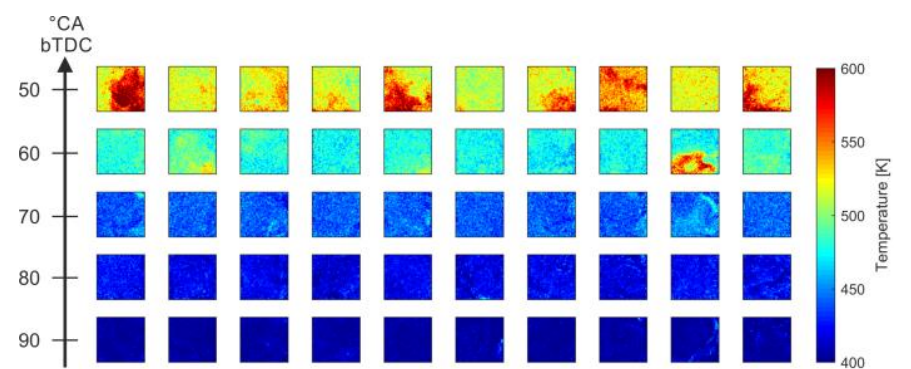

Figure 5 Fired TC-PLIF temperature measurements across the $9 \times 10 \mathrm{~mm}$ region detailed in Figure 2 for GDI-30 operation. 10 single-shot images are displayed for each of 5 crank angle timings during the compression stroke.

TC-PLIF temperature fields recorded during the compression stroke for fired GDI-30 operation show temperature inhomogeneity for later crank angles $\left(50^{\circ} \mathrm{CA}\right.$ and $60^{\circ} \mathrm{CA}$ bTDC), with mm-scale regions of high temperature $10-15 \%$ hotter than the surrounding bulk gas [Figure 5]. In contrast, earlier crank angles $\left(90^{\circ} \mathrm{CA}\right.$ to $70^{\circ} \mathrm{CA}$ bTDC) display weak inhomogeneity of approximately $6 \%$, on a similar scale to the background noise fluctuations of $4 \%$.
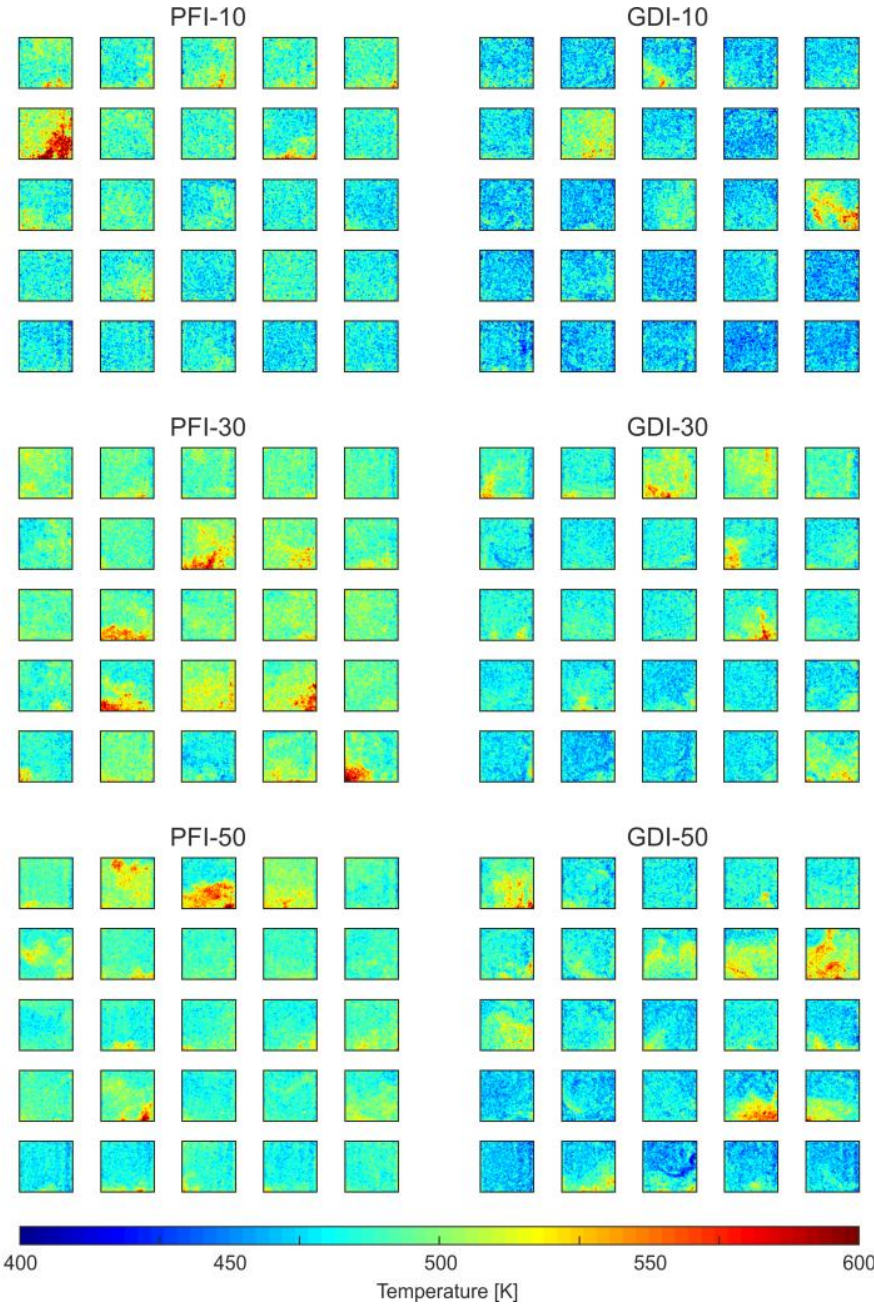

Figure 6 Fired TC-PLIF temperature measurements across the 9 x $10 \mathrm{~mm}$ region detailed in Figure 2 for PFI-10, GDI-10, PFI-30, GDI-30, PFI-50 and GDI-50. For each condition, 25 single-shot images are displayed from a dataset of 100 measurements performed at $50^{\circ} \mathrm{CA}$ bTDC.

To investigate the dependence of the measured temperature inhomogeneity on injection strategy and tracer number density, 100 TC-PLIF and LIGS measurements were performed at $50^{\circ} \mathrm{CA}$ bTDC

$01 / 14 / 2019$ 
for fired operation with the 6 combinations of fuel composition and injection strategy detailed in Table 1 [Figure 6].

Increasing the toluene content of the fuel increases the fluorescence intensity and the signal-to-noise ratio of the TC-PLIF technique. Correspondingly for the current engine conditions and imaging geometry, $10 \%$ toluene represents a lower practical limit for the toluene content of the fuel in order to produce sufficient fluorescence emission within the two TC-PLIF spectral windows. The toluene content of the fuel and the injection strategy have little apparent effect on the intensity, location or frequency of occurrence of the measured hot-spots as the temperature fields for the 6 datasets of Figure 6 show qualitatively consistent characteristics. Both the spatially-averaged mean temperature and the coefficient of variation are higher for the lower half of the images $(\sim 540 \mathrm{~K}, \pm 4.0 \%)$ compared to the upper half $(\sim 525 \mathrm{~K}, \pm 3.2 \%)$ for all fuel types and injection strategies, implying the hotspots occur more frequently in this lower region. Further analysis of the spatial distribution of the temperature inhomogeneity is performed in the Proper Orthogonal Decomposition section of this work.

\section{Validation of optical measurements}
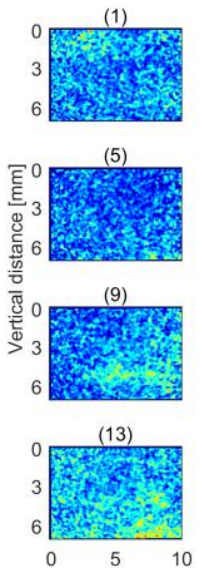

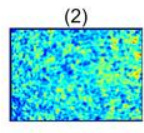

(6)

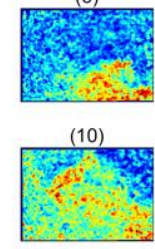

(14)

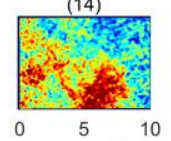

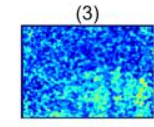

(7)

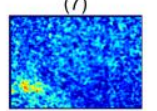

(11)
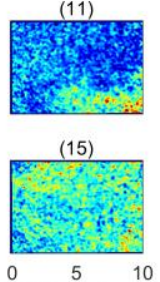
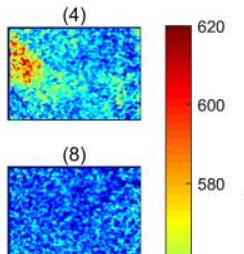

(12)

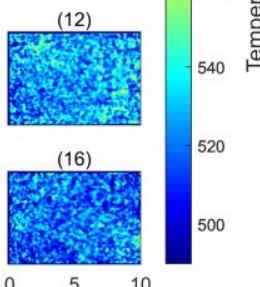

a)

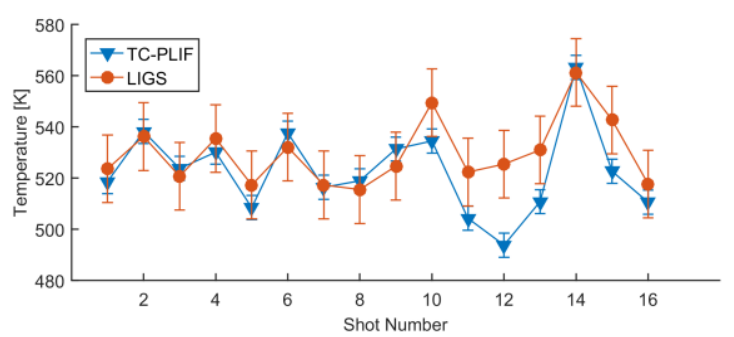

Figure 7 a) Fired TC-PLIF temperature measurements performed at $50^{\circ} \mathrm{CA}$ bTDC for PFI-30 operation, b) LIGS and TC-PLIF temperatures for the 16 measurements of a). TC-PLIF temperatures in b) are spatial averages across the LIGS region. Errorbars correspond to the standard deviation of 20 LIGS measurements and pixel-wise TC-PLIF temperatures respectively for motored operation at $50^{\circ} \mathrm{CA}$ bTDC.

One possible explanation for the temperature inhomogeneity observed in the TC-PLIF fired datasets is incomplete mixing of the hot exhaust residuals, trapped within the cylinder after the exhaust valves close, with the incoming fresh charge. However, this raises the question of whether there is potential for compositional bias of the temperature fields by the combustion products. TC-PLIF relies on the in-cylinder mixture containing no or negligible quantities of fluorescing species aside from the tracer species, in this case toluene. For motored operation this condition is satisfied by the mixture of toluene, iso-octane and air. For fired operation, combustion products Page 7 of 14 may include Polycyclic Aromatic Hydrocarbons (PAH) which fluoresce at similar wavelengths to toluene and would bias the derived TC-PLIF temperatures if present in significant quantities.

Operation of two independent optical diagnostics offers the opportunity for validation of the measurements derived from each technique. In this work TC-PLIF data is calibrated using LIGS based on multi-cycle average temperatures. This leaves the shot-by-shot variations in LIGS and TC-PLIF results at a given crank angle as independent measurements of temperature. LIGS is unaffected by variations in the fluorescent properties of the fuel-air mixture, so the strong shot-by-shot correlation of the LIGS and TC-PLIF temperatures at the LIGS measurement location [Figure 7b] suggests the apparent hotspots of Figure $7 \mathrm{a}$ are indeed regions of higher temperature as opposed to compositional variation.

\section{Combustion variability}

A sample of the pressure traces from the PFI tests and the GDI tests is shown in Figure 8. The PFI cycles show much less variability in peak cylinder pressure and combustion phasing and duration. In contrast the variation in combustion timing in the GDI cases is clearly seen from the pressure traces, with combustion occurring late in the expansion stroke in some cases.

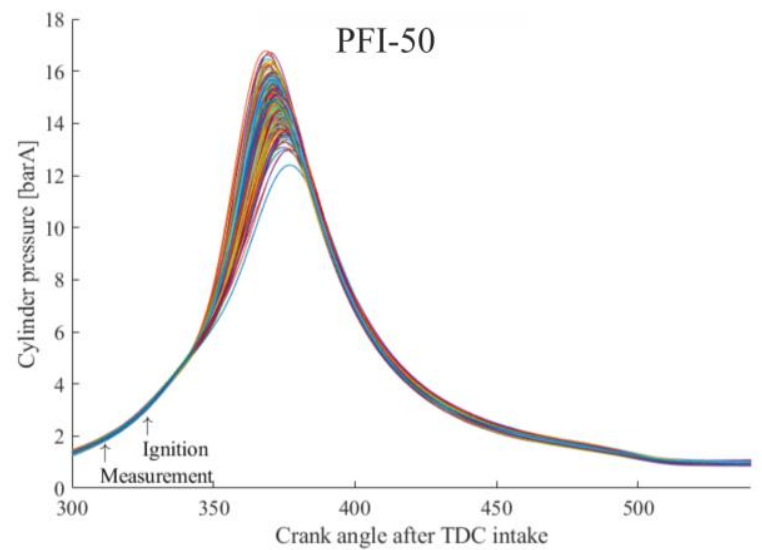

a)

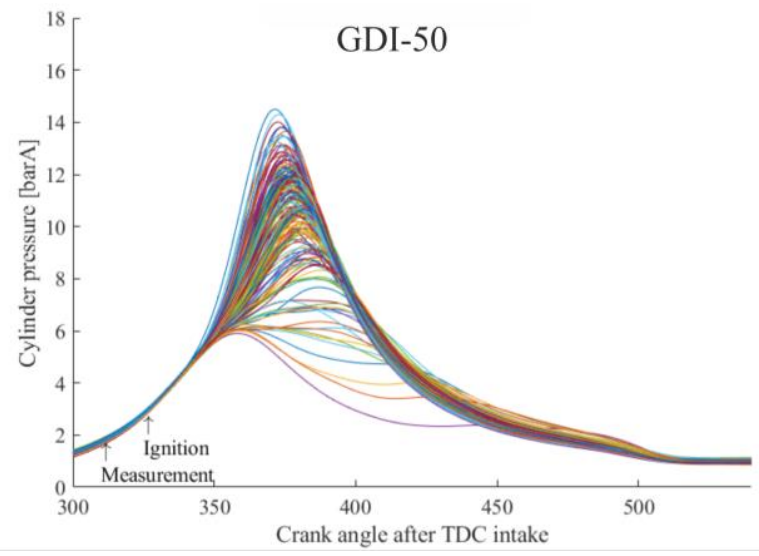

b)

Figure 8 Distribution of cylinder pressure traces for a) PFI-50 and b) GDI50. Only cycles where a TC-PLIF measurement was taken are included ( 88 cycles, each with a separation of 10 cycles). Each line represents the cylinder pressure from one cycle.

The mass fraction burn (MFB) durations are shown in Figure 9, for both PFI-50 and GDI-50 operation. These are plotted against cycle number from the start of the experiment. The range of MFB durations for these experiments were in good agreement with previous experiments using the same engine [79]. The CA10 and CA50 values are more tightly grouped for the PFI tests, reflecting the form of the

$01 / 14 / 2019$ 
pressure trace in Figure 8. Across all 1000 cycles where pressure data was gathered, the standard deviation for CA50 during PFI was $1.2^{\circ} \mathrm{CA}$ for each of the three fuels tested, whereas during GDI operation the figure was between $3.5^{\circ} \mathrm{CA}$ and $4^{\circ} \mathrm{CA}$. In contrast there is less distinction in the variability of the timing of the end of combustion between the two injection methods.

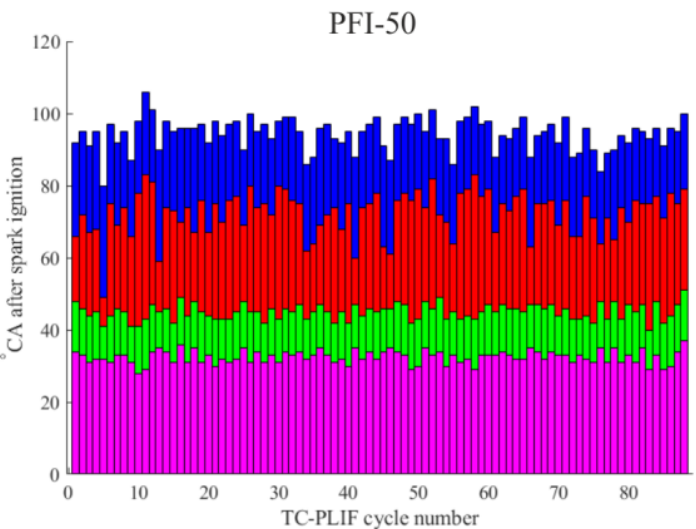

a)

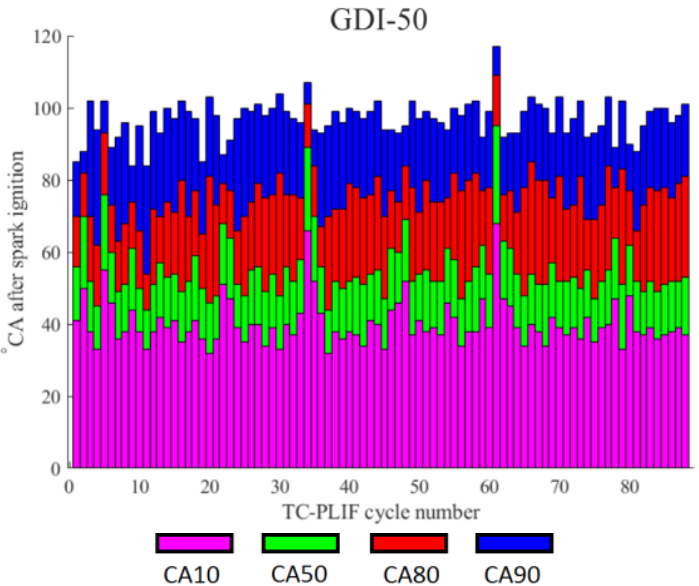

Figure 9 Distribution of combustion duration metrics CA10, CA50, CA80 and CA90 for a) PFI-50 and b) GDI-50. Only cycles where a TC-PLIF measurement was taken are shown in the charts

Some of the GDI cycles show a particularly late value of CA10 and CA50, contributing to the variability in the pressure trace and peak cylinder pressure, and the standard deviations of combustion timing for these burn durations. There is lower variability in the time between CA10 and CA50 (10-50\% MFB duration, represented by the height of the green band) than the time of CA10, indicating that the main variability is seen in a delay to the start of combustion. Cycles with a late CA10 value were also likely to exhibit a late CA80 and CA90 value, indicating that combustion lasted longer into the expansion stroke. The net IMEP for these later burning cycles is not particularly lower than on any other cycle. In addition, after analysis for completeness of combustion, following the methodology of Ball et al. [80], there was no significant trend between completeness of combustion and any burn duration or peak cylinder pressure. Therefore, it is assumed that the GDI cycles exhibiting a late combustion phasing, and associated low peak pressure, did have a significant fuel burn, and these cycles are included in subsequent analysis.

\section{POD Analysis}

\section{Eliminating Time Dependence of the Temperature Measurements}

The spatially averaged TC-PLIF temperatures of the GDI-50 data set show a strong positive correlation $\left(R_{S}=0.486, p=2.13 \times 10^{-6}\right.$, [Equation 7]) with the cycle number [Figure 10]. Such significant correlation can be also observed in the PFI-50 data set, confirming that the measurements were taken while the engine was still warming up in agreement with the LIGS measurements of Figure 4.

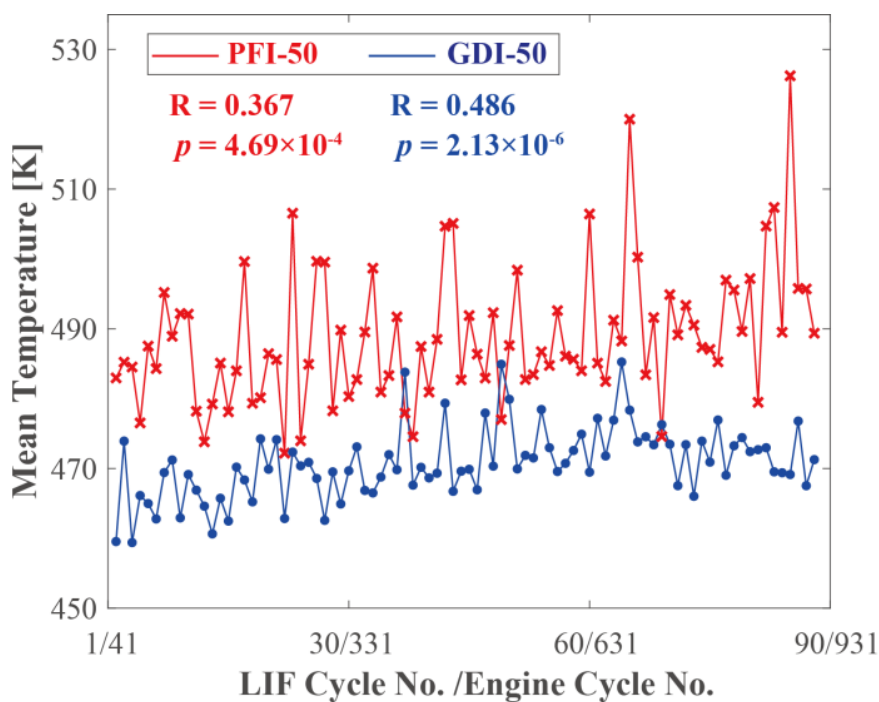

Figure 10 Combustion parameters versus cycle numbers with Spearman's ranked correlation coefficient $R$ and corresponding $p$ value. Red lines with crosses: for PFI-50 data set; Blue lines with dots: for GDI-50 data set.

The underlying principle of POD ensures successive summed squared mode coefficient maximization [Equation 10], and thus the lowerorder POD modes will favour the data with higher temperature. In our case, the increasing drift in temperature may in turn skew the POD results, as the resulting POD modes will preferentially reflect later cycles (with higher temperature) rather than the overall behaviour of the ensemble. Such time-dependency ought to be eliminated prior to POD analysis. A practical way would be to subtract the spatial average from each temperature field [Equation 8]. The two-sided test of significance confirmed that the resulting fluctuating temperature fields have no correlation with cycle number.

\section{Candidate Outlier Cycle Detection and Removal}

The calculation of POD ensures successive maximization of the sum of squared coefficients over all the cycles, which does not restrict the contribution of any individual cycle. Shen et al. [81] observed an outlier cycle with excessively high contribution to the third POD mode when analysing Particle Image Velocimetry measurements on the tumble plane. The outlier cycle skewed the third POD mode, and the mode shape altered significantly after removing it. Therefore, they proposed an algorithm to detect such outliers and suggested to remove them in order to maintain reliability of the POD results. Gao et al. [82] later confirmed that such outlier cycles may affect the interpretation of the POD results using velocity data at another crank angle, and found that the outlier cycle of that crank angle resulted from overexposure during the measurement. One would expect such outliers may also exist in our temperature data sets, and we now 
follow their procedure to detect the candidate outlier cycles ${ }^{2}$. The result of considering the PFI-30 data set is presented here as an example.

The algorithm is based on two test metrics: the contribution to a particular POD mode (quantified by squared mode coefficients) and the similarity between mode shape and temperature fields (quantified by the absolute value of the relevance index [Equation 11]). The squared Mode 1 coefficients span a wide range from $1.6 \times 10^{3}$ to $1.7 \times 10^{8}$ [Figure 11]. However, most are less than $3.3 \times 10^{7}$ except for an excessively high value for TC-PLIF Cycle No. 72, which is more than eight standard deviations from the mean. The cumulative sum of the squared Mode 1 coefficients (magenta line) suggests that this cycle (marked in red) alone contributes $27.2 \%$ of the total sum over all the cycles, while the other 87 cycles only cover the remaining $72.8 \%$ share. The fluctuating temperature field of the highlighted cycle is also excessively more similar to the POD mode 1 as the magnitude of its relevance index is more than two standard deviations higher than the mean value [Figure 11, right]. The scatter plot of the two metrics further illustrates that this cycle is indeed a candidate outlier, with excessively high contribution to Mode 1 and high similarity versus Mode 1, deserving further examination.
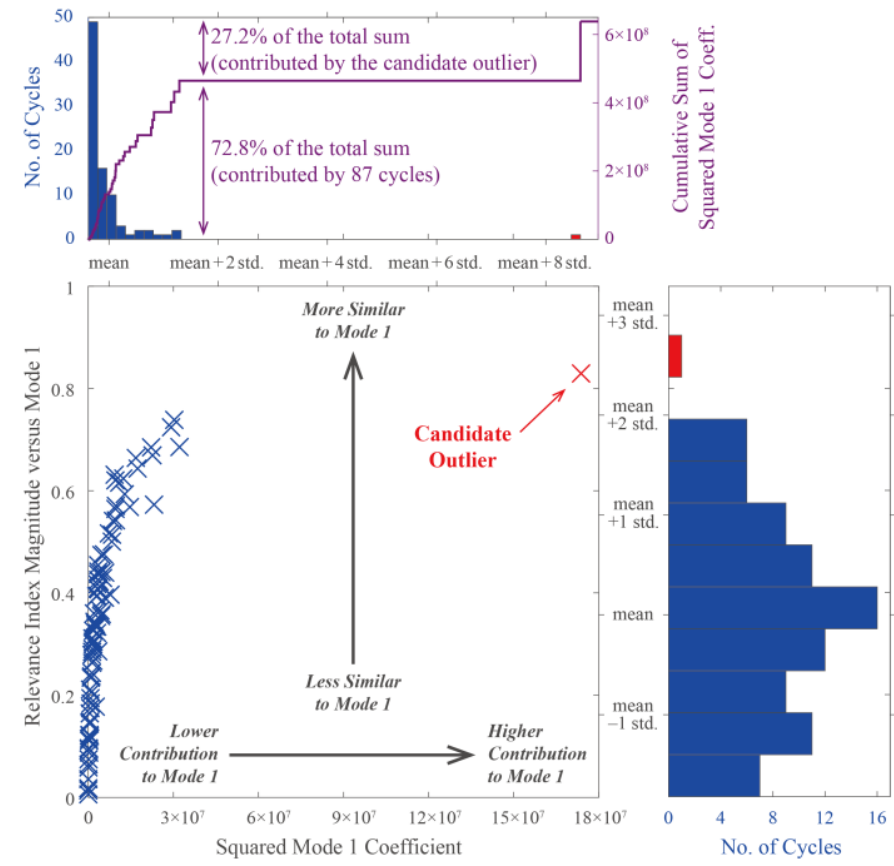

Figure 11 Outlier detection metrics for PFI-30 data set. Top: Histogram of squared Mode 1 coefficients; Bottom-Left: Scatter plot between squared Mode 1 coefficients and relevance index magnitude versus Mode 1; Right: Histogram of relevance index magnitudes versus Mode 1.

The fluctuating temperature field of the candidate outlier is very different from other PFI-30 cycles [Figure 12a]. The typical fluctuation fields (PLIF Cycles No. 71 and 73) show only small deviations from uniformity, whereas the spatial temperature fluctuation during the candidate outlier cycle (PLIF Cycle No. 72) is

\footnotetext{
2 Note that the term "candidate" is used here. We prefer not to remove the outliers detected by Shen et al.'s algorithm [81] directly, as they could either be actual outliers or real measurements with high fluctuations. It is more reasonable to remove a candidate outlier if some evidence can be provided for it being an anomalous outlier, which will be discussed in the following paragraphs.
}

more exaggerated. The upper half shows a strong negative fluctuation, while the lower-right corner has large positive values. The absolute temperatures of the original measurement of the candidate outlier cycle, before subtraction of the spatial mean, also show abnormal behaviour. The temperature near the lower-right corner is approximately $120 \mathrm{~K}$ higher than the spatial mean, compared to typically $20 \mathrm{~K}$ higher for cycles with similarly located hot spots. The pressure trace [Figure 12b] and combustion data [Figure 12c] during the candidate outlier cycle, however, are similar to other cycles. Therefore it is reasonable to presume the candidate outlier cycle could have been a flawed measurement, and this cycle is excluded from the PLIF data set in our POD calculation. The outlier detection was conducted in all the six data sets, and four outlier cycles were removed (out of a total of 453 cycles). (a)

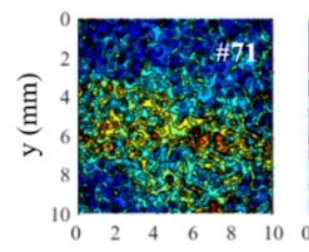

(b)

Pressure Traces

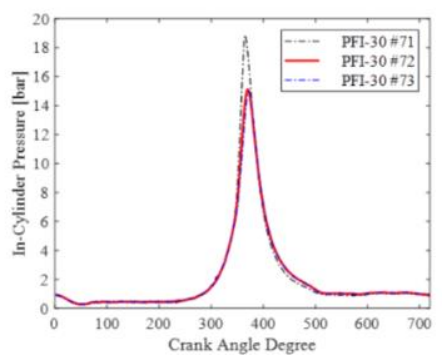

$\mathrm{x}(\mathrm{mm})$
PFI-30 Temp. Field

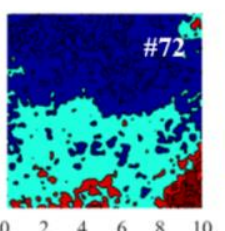

(c)
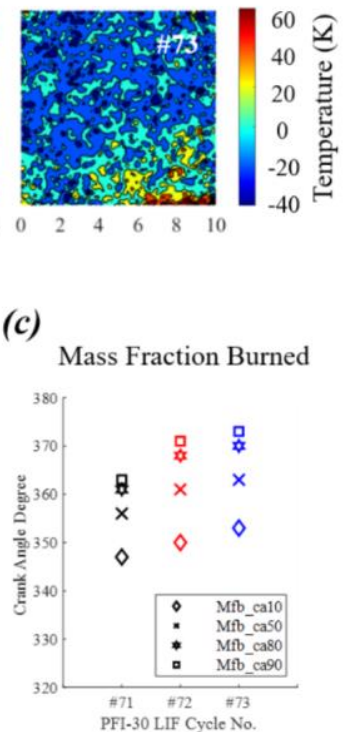

Figure 12 Temperature fields and combustion data for the fired PFI-30 condition. (a) Fluctuating temperature fields centred around the spatial average of the corresponding absolute temperature field. The colour scale has been selected to represent fluctuations present in cycles 71 and 73 , leading to saturation of the scale for cycle 72 (candidate outlier). (b) Pressure traces. (c) Crank angle degree at which $x \%$ of mass is burned.

\section{POD Modes}

The POD eigenvalues quantify the amount of cyclic variation captured by each POD mode. The eigenvalues are normalized by the sum over all the POD modes in order to provide a fair comparison between different engine operating conditions [Figure 13]. The first mode for the PFI-50 data set (red crosses) alone represents $90 \%$ of the variation, while the sum of the first ten modes for the PFI-10 data set (magenta solid line) only feature about $80 \%$ of the variation. In other words, more modes are needed to reach the same fluctuation level when less toluene is added into the fuel. The results suggest that the temperature field fluctuations quantified by POD are stronger for lower toluene concentrations within the fuel. This could be a result of either stronger cyclic variability in the temperature fields for GDI-10 and PFI-10 operation, or a result of the reduced signal strength due to the reduction in toluene number density compared the $30 \%$ and $50 \%$ toluene fuels. 


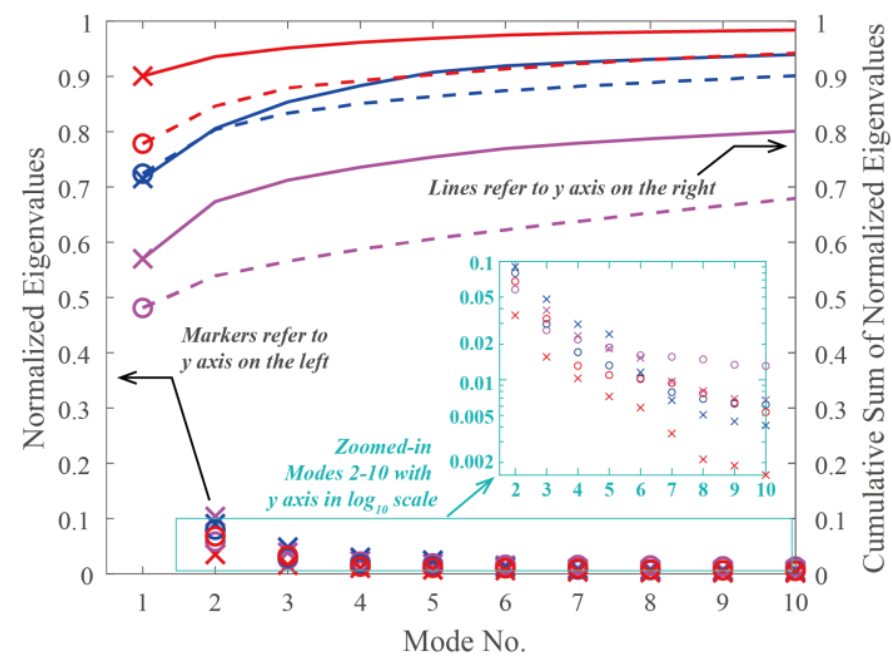

Figure 13 Normalized eigenvalues at each POD mode. Only the first ten POD modes are presented here. Magenta crosses: PFI-10 data set; Blue crosses: PFI-30 data set; Red crosses: PFI-50 data set; Magenta circles: GDI10 data set; Blue circles: GDI-30 data set; Red circles: GDI-50 data set. The solid and dashed lines refer to the cumulative sum starting from Mode 1 for PFI and GDI data sets, respectively.

The cumulative sum of normalized eigenvalues of GDI data sets (dashed lines) are generally lower than those of PFI data sets (solid lines) at the same mode number [Figure 13], suggesting that the cyclic variation in temperature is stronger in direct injection cases. While early injection at $280^{\circ} \mathrm{CA}$ bTDC under the conditions of this work aims to produce a nominally homogeneous fuel-air distribution, the fuel-air mixing process may have an impact on the temperature distribution within the cylinder at $50^{\circ} \mathrm{CA}$ bTDC. When the fuel is injected directly into the cylinder, the initially inhomogeneous fuel distribution will cause spatial variations in charge cooling. Due to the limited time available for subsequent mixing, this temperature inhomogeneity may persist until $50^{\circ} \mathrm{CA}$ bTDC. In contrast, for PFI operation the fuel is injected into the intake plenum, allowing more time for mixing and ensuring a more homogenous mixture during the intake stroke, which reduces the cycle-to-cycle temperature variation.

In addition to the direct effects of fuel injection and evaporation, incomplete mixing of the hot residual exhaust gases could be a potential candidate for the origin of the observed hot spots. Given the significantly increased variation in combustion timing for GDI compared to PFI operation in Figure 8 and Figure 9, the increased cyclic fluctuations for GDI identified by POD may also be in part due to the effect of GDI on combustion rather than charge cooling alone.

The normalized eigenvalues also allow us to examine the importance of each POD mode under the same working condition [Figure 13]. The eigenvalues are monotonically decreasing with respect to mode number as a result of successive maximization [Equation 10]. Most of the cyclic variation is concentrated in the first POD mode under all working conditions. For example, the POD analysis on the PFI-30 data set (consists of 88 cycles) gives a total of 88 POD modes, and $76.8 \%$ of the variation is captured by the first mode, whereas the remaining 87 modes only collect less than a quarter of the variation (blue crosses). Therefore, the shapes of the first POD modes illustrate the coherent structure of the fluctuating temperature fields.

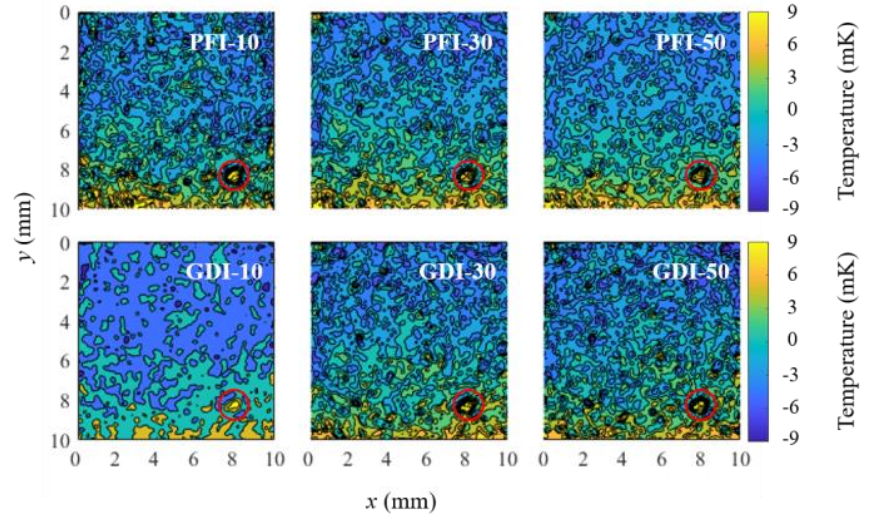

Figure 14 The first POD Modes. Top row (from left to right): for the PFI-10, PFI-30 and PFI-50 data sets; Bottom row (from left to right): for the GDI-10, GDI-30 and GDI-50 data sets. The red circles highlight a consistent spot due to sensor damage.

The first POD mode shows a top-bottom temperature gradient under all operating conditions [Figure 14]. The values on the upper half of the field of view are almost all negative, as opposed to the lower half with mostly positive values. In our calculation, the sign of the mode is defined such that more than half of the cycles have positive mode coefficients. Therefore, this gradient illustrates that the temperature is generally lower than the spatial average towards the cylinder head, and higher than the average towards the piston, across the $10 \mathrm{~mm} \times 10 \mathrm{~mm}$ field of view.

Besides cyclic variation, the first POD mode also identifies spots [Figure 14, red circles], whose values are consistently higher than the neighbouring areas. The spatial locations of these spots are identical in different operating conditions, indicating that this phenomenon may be caused by a systematic error during the measurement rather than the nature of the in-cylinder temperature field. This location coincides with a small region of sensor damage which slightly reduces the sensitivity of the intensified CCD camera for the shorterwavelength spectral window, leading to the increase in reported temperature identified by the first POD modes.

Unlike the first modes, the second POD modes have left-right gradients [Figure 15], meaning that the secondary important cyclic variation is the asymmetric fluctuation between the inlet and exhaust sides of the field of view. The competition between the top-bottom gradient illustrated in the first POD mode and the left-right fluctuation shown in mode 2 can be quantified using the difference between eigenvalues [Table 3]. The difference between the topbottom and left-right gradients is larger when the toluene level is high (PFI-50 and GDI-50), compared to the lower toluene concentration data sets (PFI-10 and GDI-10). Similarly to Figure 13, this indicates that the temperature field fluctuations are less well represented by mode 1 for GDI-10 and PFI-10 compared to the higher toluene content conditions. This could be a consequence of the reduction in signal strength compared to the higher toluene content fuels, or a physical change in the complexity of the temperature field. 


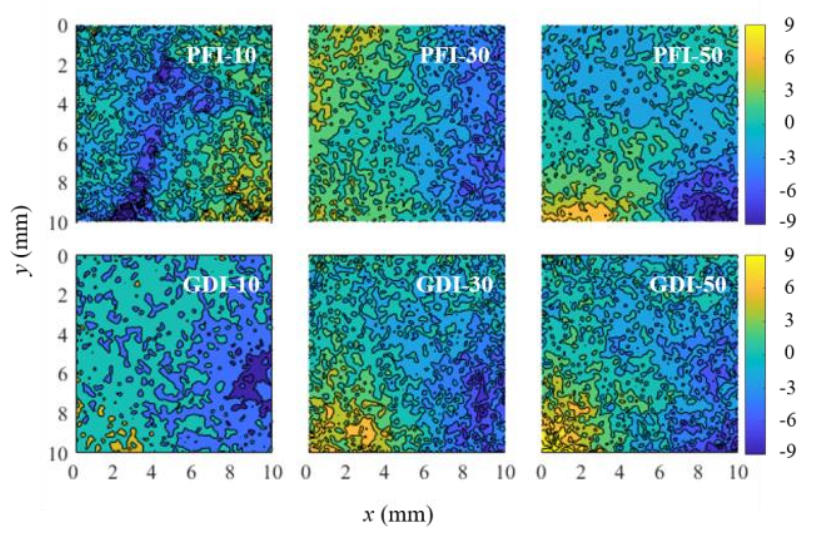

Figure 15 The second POD Modes. Top row (from left to right): for the PFI10, PFI-30 and PFI-50 data sets; Bottom row (from left to right): for the GDI10 , GDI-30 and GDI-50 data sets.

Table 3 Eigenvalues for the first two POD modes and their difference

\begin{tabular}{cccc}
\hline $\begin{array}{c}\text { Operating } \\
\text { Condition }\end{array}$ & $\begin{array}{c}\text { Eigenvalue of } \\
\text { Mode 1 }\end{array}$ & $\begin{array}{c}\text { Eigenvalue of } \\
\text { Mode 2 }\end{array}$ & $\begin{array}{c}\text { Difference between } \\
\text { eigenvalues }\end{array}$ \\
\hline PFI-10 & 0.57 & 0.10 & 0.47 \\
GDI-10 & 0.48 & 0.06 & 0.42 \\
PFI-30 & 0.72 & 0.09 & 0.63 \\
GDI-30 & 0.72 & 0.08 & 0.64 \\
PFI-50 & 0.90 & 0.04 & 0.86 \\
GDI-50 & 0.78 & 0.07 & 0.71 \\
\hline
\end{tabular}

\section{Correlation between Mode 1 coefficient and combustion parameters}

Two-sided tests of significance were conducted on the six fuel and injection conditions to investigate any correlation between the combustion parameters derived from pressure measurements and the temperature field fluctuations represented by the POD mode 1 coefficients. The combustion parameters were selected from the same engine cycle during which the temperature was measured $\left(50^{\circ} \mathrm{CA}\right.$ after the TC-PLIF measurement) and from the previous engine cycle $\left(670^{\circ} \mathrm{CA}\right.$ before the TC-PLIF measurement).

Table $4 \quad p$ values for two-sided tests of significance between Mode 1 coefficients and combustion data.

\begin{tabular}{ccccc}
\hline $\begin{array}{c}\text { Combustion } \\
\text { Data }\end{array}$ & $\begin{array}{c}\text { GDI-10 } \\
50^{\circ} \mathrm{CA} \\
\text { after }\end{array}$ & $\begin{array}{c}\text { GDI-10 } \\
670^{\circ} \mathrm{CA} \\
\text { before }\end{array}$ & $\begin{array}{c}\text { GDI-50 } \\
50^{\circ} \mathrm{CA} \\
\text { after }\end{array}$ & $\begin{array}{c}\text { GDI-50 } \\
670^{\circ} \mathrm{CA} \\
\text { before }\end{array}$ \\
\hline net IMEP & 0.48 & 0.65 & 0.09 & 0.40 \\
max Pressure & 0.11 & 0.56 & 0.09 & 0.09 \\
MFB-CA10 & 0.04 & 0.36 & 0.06 & 0.06 \\
MFB-CA50 & 0.10 & 0.40 & 0.04 & 0.11 \\
MFB-CA80 & 0.12 & 0.45 & 0.06 & 0.08 \\
MFB-CA90 & 0.15 & 0.43 & 0.05 & 0.08 \\
\hline
\end{tabular}

For all conditions, the combustion parameters $670^{\circ} \mathrm{CA}$ before the temperature measurement have no correlation with the POD first mode coefficients. This indicates that the combustion process in the previous cycle, as far as can be quantified via the pressure trace, does Page 11 of 14 not have a strong influence on the temperature field of the current cycle at the chosen measurement timing and location. This could be due to the air motion created by the exhaust and intake processes having a greater influence on fluctuations in the temperature field than variations in the previous combustion event.

No correlations between POD first mode coefficient and combustion parameters were found within the same engine cycle. It is therefore not possible to draw conclusions about the influence of fluctuations in the temperature field at $50^{\circ} \mathrm{CA}$ bTDC on subsequent combustion parameters other than that they are in general uncorrelated.

\section{Conclusions}

Cycle-by-cycle variations of Two-Colour PLIF temperature distributions obtained during the compression stroke of a firing spark ignition engine have been analysed using Proper Orthogonal Decomposition, after being calibrated in-situ with simultaneous Laser-Induced Grating Spectroscopy measurements.

Temperature inhomogeneity at $50^{\circ} \mathrm{CA}$ bTDC was observed for fired operation and validated using shot-by-shot comparison of the temperatures derived by the TC-PLIF and LIGS techniques independently. Occasional mm-scale regions of high temperatures $10-15 \%$ hotter than the surrounding bulk gas contrasted with the homogeneous temperature distributions observed for motored operation. Similar results were obtained for PFI and GDI injection strategies, using two-component fuels with either $10 \%, 30 \%$ or $50 \%$ toluene by volume in iso-octane.

Use of the relevance index to quantify similarity between POD modes and temperature fields of individual cycles, combined with consideration of the POD mode coefficients enabled candidate outlier cycles to be readily identified for further examination and removal.

Cycle-to-cycle fluctuations quantified by POD mode coefficients were found to be stronger for GDI operation than PFI. Analysis of the pressure traces also identified high variability of combustion for GDI operation compared to PFI, however low-order POD mode coefficients were found to be in general uncorrelated with pressurederived combustion parameters, fuel injection strategy or fuel composition. The $50^{\circ} \mathrm{CA}$ separation between the TC-PLIF temperature measurement and combustion timing, combined with the small field of view as a fraction of the cylinder cross-section, is likely to obscure any potential correlations that may have been apparent were information across a larger area or at later crank angles available.

\section{Acknowledgements}

The authors are grateful for support from the Engineering and Physical Science Research Council (EPSRC) UK, from BP Formulated Products Technology and from Jaguar Land Rover Ltd. This work was further supported by the Royal Academy of Engineering under the Newton Research Collaboration Programme (Distinguished Visiting Fellowship, DVF1415/2/10).

\section{References}

1. Johnson, T. and Joshi, A., "Review of Vehicle Engine Efficiency and Emissions," SAE Technical Paper 2018-01-0329, 2018.

2. Stone, R., Introduction to Internal Combustion Engines (fourth edition), London: Palgrave Macmillan, 2012. 
3. Wang, Z., Liu, H. and Reitz, R., "Knocking combustion in spark-ignition engines," Prog. Energy Combust. Sci. 61: 78-112, 2017.

4. Zhen, X., Wang, Y., Xu, S., Zhu, Y. et al., "The engine knock analysis - An overview," Appl. Energy 92: 628-636, 2012.

5. Kalghatgi, G., "Developments in internal combustion engines and implications for combustion science and future transport fuels," Proc. Combust. Inst. 35(1): 101-115, 2015.

6. Heywood, J., Internal Combustion Engine Fundamentals (second edition), New York: McGraw-Hill Education, 2018.

7. Kasseris, E. and Heywood, J., "Charge Cooling Effects on Knock Limits in SI DI Engines Using Gasoline/Ethanol Blends: Part 1-Quantifying Charge Cooling," SAE Technical Paper 2012-01-1275, 2012.

8. Li, T., Gao, Y., Wang, J. and Chen, Z., "The Miller cycle effects on improvement of fuel economy in a highly boosted, high compression ratio, direct-injection gasoline engine: EIVC vs. LIVC," Energy Convers. Manag. 79: 59-65, 2014.

9. Wei, H., Zhu, T., Shu, G., Tan, L. et al., "Gasoline engine exhaust gas recirculation - A review," Appl. Energy 99: 534544, 2012.

10. Eckbreth, A., Laser Diagnostics for Combustion Temperature and Species (second edition), Amsterdam: Gordon and Breach Publishers, 1996.

11. Ladommatos, N. and Zhao, H., Engine Combustion Instrumentation and Diagnostics, Warrendale: SAE International, 2001.

12. Kohse-Höinghaus, K. and Jeffries, J., Applied Combustion Diagnostics (first edition), New York: Taylor \& Francis, 2002.

13. Schulz, C., Dreizler, A., Ebert, V., and Wolfrum, J., "Combustion Diagnostics," in Springer Handbook of Experimental Fluid Mechanics, ed. Tropea, C., Yarin, A. and Foss, J., 1241-1315. Berlin: Springer-Verlag, 2007.

14. Pischinger, S., Günther, M. and Budak, O., "Abnormal combustion phenomena with different fuels in a spark ignition engine with direct fuel injection," Combust. Flame 175: 123$137,2017$.

15. Goyal, G., Warnatz, J. and Maas, U., "Numerical studies of hot spot ignition in $\mathrm{H} 2-\mathrm{O} 2$ and $\mathrm{CH} 4-$ air mixtures," Int. Symp. Combust. 23(1): 1767-1773, 1990.

16. Bauerle, B., Hoffmann, F., Behrendt, F. and Warnatz, J., "Detection of hotspots in the end gas of an internal combustion engine using two-dimensional LIF of formaldehyde," Int. Symp. Combust. 25(1): 135-141, 1994.

17. Scott, B., Willman, C., Williams, B., Ewart, P. et al., "InCylinder Temperature Measurements Using Laser Induced Grating Spectroscopy and Two-Colour PLIF," SAE Int. J. Engines 10(4): 2191-2201, 2017.

18. Schulz, C. and Sick, V., "Tracer-LIF diagnostics: Quantitative measurement of fuel concentration, temperature and fuel/air ratio in practical combustion systems," Prog. Energy Combust. Sci. 31(1): 75-121, 2005.

19. Peterson, B., Baum, E., Böhm, B., Sick, V. et al., "Evaluation of toluene LIF thermometry detection strategies applied in an internal combustion engine," Appl. Phys. B-Lasers Opt. 117(1): 151-175, 2014.

20. Kaiser, S., Schild, M. and Schulz, C., "Thermal stratification in an internal combustion engine due to wall heat transfer measured by laser-induced fluorescence," Proc. Combust. Inst. 34(2): 2911-2919, 2013.

21. Luong, M., Zhang, R., Schulz, C. and Sick, V., "Toluene laserinduced fluorescence for in-cylinder temperature imaging in internal combustion engines," Appl. Phys. B-Lasers Opt. 91: 669-675, 2008.

22. Luong, M., Koban, W. and Schulz, C., "Novel strategies for imaging temperature distribution using Toluene LIF," J. Phys.: Conf. Ser. 45: 133-139, 2006.

Page 12 of 14
23. Peterson, B., Baum, E., Böhm, B., Sick, V. et al., "High-speed PIV and LIF imaging of temperature stratification in an internal combustion engine," Proc. Combust. Inst. 34(2): 3653-3660, 2013.

24. Thurber, M. and Hanson, R., "Simultaneous imaging of temperature and mole fraction using acetone planar laserinduced fluorescence," Exp. Fluids 30(1): 93-101, 2001.

25. Einecke, S., Schulz, C. and Sick, V., "Measurement of temperature, fuel concentration and equivalence ratio fields using tracer LIF in IC engine combustion," Appl. Phys. B-Lasers Opt. 71(5): 717-723, 2000.

26. Rothamer, D., Snyder, J., Hanson, R. and Steeper, R., "Optimization of a tracer-based PLIF diagnostic for simultaneous imaging of EGR and temperature in IC engines," Appl. Phys. B-Lasers Opt. 99(1-2): 371-384, 2009.

27. Thurber, M. and Hanson, R., "Pressure and composition dependences of acetone laser-induced fluorescence with excitation at 248, 266, and $308 \mathrm{~nm}, "$ Appl. Phys. B-Lasers Opt. 69(3): 229-240, 1999.

28. Grossmann, J., Monkhouse, P., Ridder, M., Sick, V. et al., "Temperature and pressure dependences of the laser-induced fluorescence of gas phase acetone and 3-pentanone," Appl. Phys. B-Lasers Opt. 62(3): 249-253, 1996.

29. Koban, W., Koch, J., Sick, V., Wermuth, N. et al., "Predicting LIF signal strength for toluene and 3-pentanone under enginerelated temperature and pressure conditions," Proc. Combust. Inst. 30(1): 1545-1553, 2005.

30. Faust, S., Tea, G., Dreier, T. and Schulz, C., "Temperature, pressure, and bath gas composition dependence of fluorescence spectra and fluorescence lifetimes of toluene and naphthalene," Appl. Phys. B-Lasers Opt. 110(1): 81-93, 2013.

31. Devillers, R., Bruneaux, G. and Schulz, C., "Investigation of toluene LIF at high pressure and high temperature in an optical engine," Appl. Phys. B-Lasers Opt. 96(4): 735-739, 2009.

32. Cundy, M., Trunk, P., Dreizler, A. and Sick, V., "Gas-phase toluene LIF temperature imaging near surfaces at $10 \mathrm{kHz}$," Exp. Fluids 51(5): 1169-1176, 2011.

33. Löffler, M., Beyrau, F. and Leipertz, A., "Acetone laser-induced fluorescence behavior for the simultaneous quantification of temperature and residual gas distribution in fired spark-ignition engines," Appl. Opt. 49(1): 37-49, 2010.

34. Bolshov, M., Kuritsyn, Y. and Romanovskii, Y., "Tunable diode laser spectroscopy as a technique for combustion diagnostics," Spectroc. Acta Pt. B-Atom. Spectr. 106: 45-66, 2015.

35. Bürkle, S., Biondo, L., Ding, C., Honza, R. et al., "In-Cylinder Temperature Measurements in a Motored IC Engine using TDLAS," Flow Turbul. Combust. 101(1): 139-159, 2018.

36. Roy, S., Gord, J. and Patnaik, A., "Recent advances in coherent anti-Stokes Raman scattering spectroscopy: Fundamental developments and applications in reacting flows," Prog. Energy Combust. Sci. 36(2): 280-306, 2010.

37. Brackmann, C., Bood, J., Afzelius, M. and Bengtsson, P-E., "Thermometry in internal combustion engines via dualbroadband rotational coherent anti-Stokes Raman spectroscopy," Meas. Sci. Technol. 15(3): R13-R25, 2004.

38. Weikl, M., Beyrau, F. and Leipertz, A., "Simultaneous temperature and exhaust-gas recirculation-measurements in a homogeneous charge-compression ignition engine by use of pure rotational coherent anti-Stokes Raman spectroscopy," Appl. Opt. 45(15): 3646-3651, 2006.

39. Beyrau, F., Bräuer, A., Seeger, T. and Leipertz, A., "Gas-phase temperature measurement in the vaporizing spray of a gasoline direct-injection injector by use of pure rotational coherent antiStokes Raman scattering," Opt. Lett. 29(3): 247-249, 2004. 
40. Seeger, T. and Leipertz, A., "Experimental comparison of single-shot broadband vibrational and dual-broadband pure rotational coherent anti-Stokes Raman scattering in hot air," Appl. Opt. 35(15): 2665-2671, 1996.

41. Hildenbrand, S., Staudacher, S., Brüggemann, D., Beyrau, F. et al., "Numerical and experimental study of the vaporization cooling in gasoline direct injection sprays," Proc. Combust. Inst. 31(2): 3067-3073, 2007.

42. Birkigt, A., Michels, K., Theobald, J., Seeger, T. et al., "Investigation of compression temperature in highly charged spark-ignition engines," Int. J. Engine Res. 12(3): 282-292, 2011.

43. Kiefer, J. and Ewart, P., "Laser diagnostics and minor species detection in combustion using resonant four-wave mixing," Prog. Energy Combust. Sci. 37(5): 525-564, 2011.

44. Williams, B., Edwards, M., Stone, R., Williams, J. et al., "High precision in-cylinder gas thermometry using Laser Induced Gratings: Quantitative measurement of evaporative cooling with gasoline/alcohol blends in a GDI optical engine," Combust. Flame 161(1): 270-279, 2014.

45. Stampanoni-Panariello, A., Kozlov, D., Radi, P. and Hemmerling, B., "Gas phase diagnostics by laser-induced gratings I. Theory," Appl. Phys. B-Lasers Opt. 81(1): 101-111, 2005.

46. Stampanoni-Panariello, A., Kozlov, D., Radi, P. and Hemmerling, B., "Gas phase diagnostics by laser-induced gratings II. Experiments," Appl. Phys. B-Lasers Opt. 81(1): 113129, 2005.

47. Hart, R., Balla, R. and Herring, G., "Nonresonant referenced laser-induced thermal acoustics thermometry in air," Appl. Opt. 38(3): 577-584, 1999.

48. Schlamp, S., Hornung, H., Sobota, T. and Cummings, E., "Accuracy and uncertainty of single-shot, nonresonant laserinduced thermal acoustics," Appl. Opt. 39(30): 5477-5481, 2000.

49. Cummings, E., "Laser-induced thermal acoustics: simple accurate gas measurements," Opt. Lett. 19(17): 1361-1363, 1994.

50. Cummings, E., Leyva, I. and Hornung, H., "Laser-induced thermal acoustics (LITA) signals from finite beams," Appl. Opt. 34(18): 3290-3302, 1995.

51. Paul, P., Farrow, R. and Danehy, P., "Gas-phase thermal-grating contributions to four-wave mixing," J. Opt. Soc. Am. B-Opt. Phys. 12(3): 384-392, 1995.

52. Williams, S., Rahn, L., Paul, P., Forsman, J. et al., "Laserinduced thermal grating effects in flames," Opt. Lett. 19(21): 1681-1683, 1994.

53. Stevens, R. and Ewart, P., "Single-shot measurement of temperature and pressure using laser-induced thermal gratings with a long probe pulse," Appl. Phys. B-Lasers Opt. 78(1): 111117, 2004.

54. Kychakoff, G., Howe, R. and Hanson, R., "Quantitative flow visualization technique for measurements in combustion gases," Appl. Opt. 23(5): 704-712, 1984.

55. Pfadler, S., Beyrau, F., Löffler, M. and Leipertz, A., "Application of a beam homogenizer to planar laser diagnostics," Opt. Express 14(22): 10171-10180, 2006.

56. Latzel, H., Dreizler, A., Dreier, T., Heinze, J. et al., "Thermal grating and broadband degenerate four-wave mixing spectroscopy of $\mathrm{OH}$ in high-pressure flames," Appl. Phys. BLasers Opt. 67(5): 667-673, 1998.

57. Brown, M. and Roberts, W., "Single-Point Thermometry in High-Pressure, Sooting, Premixed Combustion Environments," J. Propul. Power 15(1): 119-127, 1999.

58. Sahlberg, A-L., Hot, D., Kiefer, J., Aldén, M. and Li, Z., "Midinfrared laser-induced thermal grating spectroscopy in flames," Proc. Combust. Inst., 36(3): 4515-4523, 2017.
59. Luers, A., Sahlberg, A-L., Hochgreb, S. and Ewart, P., "Flame thermometry using laser-induced-grating spectroscopy of nitric oxide," Appl. Phys. B-Lasers Opt. 124(3): 1-13, 2018.

60. Luers, A., Sahlberg, A-L., Förster, F., Willman, C. et al., "High precision measurement of combustion parameters in flames and engines using Laser Induced Grating Scattering, LIGS," OSA Technical Digest ETh2A.2, in Light, Energy and the Environment, 2017.

61. Roshani, B., Flügel, A., Schmitz, I., Kozlov, D. et al., "Simultaneous measurements of fuel vapor concentration and temperature in a flash-boiling propane jet using laser-induced gratings," J. Raman Spectrosc. 44(10): 1356-1362, 2013.

62. Selcan, C., Sander, T., Altenhöfer, P., Koroll, F. et al., "Stagnation Temperature Measurements in a Shock-Tunnel Facility Using Laser-Induced Grating Spectroscopy," $J$. Thermophys. Heat Transf. 32(1): 226-236, 2017.

63. Förster, F., Crua, C., Davy, M. and Ewart, P., "Temperature measurements under diesel engine conditions using laser induced grating spectroscopy," Combust. Flame, 199, 249-257, 2019.

64. Williams, B., Ewart, P., Wang, X., Stone, R. et al., "Quantitative planar laser-induced fluorescence imaging of multi-component fuel/air mixing in a firing gasoline-direct-injection engine: Effects of residual exhaust gas on quantitative PLIF," Combust. Flame 157(10): 1866-1878, 2010.

65. Lumley, J., "The Structure of inhomogeneous Turbulent Flows," in Atmospheric turbulence and radio wave propagation, ed. Yaglom, A. and Tatarsky, A., 166-178. Moscow: Nauka, 1967.

66. Moin, P. and Moser, R., "Characteristic-eddy decomposition of turbulence in a channel," J. Fluid. Mech. 200: 471-509, 1989.

67. Rempfer, D. and Fasel, H., "Evolution of three-dimensional coherent structures in a flat-plate boundary layer," J. Fluid. Mech. 260: 351-375, 1994.

68. Erdil, A., Kodal, A. and Aydin, K., "Decomposition of Turbulent Velocity Fields in an SI Engine," Flow Turbul. Combust. 68: 91-110, 2002.

69. Buhl, S., Hartmann, F. and Hasse, C., "Identification of LargeScale Structure Fluctuations in Engines using POD-Based Conditional Averaging," Oil Gas Sci. Technol. - Rev. IFP Energies nouvelles 71: 1, 2016.

70. Roudnitzky, S., Druault, P. and Guibert, P., "Proper orthogonal decomposition of in-cylinder engine flow into mean component, coherent structures and random Gaussian fluctuations," $J$. Turbul. 7: N70, 2006.

71. Zhuang, H. and Hung, D., "Characterization of the effect of intake air swirl motion on time-resolved in-cylinder flow field using quadruple proper orthogonal decomposition," Energy Conv. Manag. 108: 366-376, 2015.

72. Epps, B. and Techet, A., "An error threshold criterion for singular value decomposition modes extracted from PIV data," Exp Fluids 48(2): 355-367, 2010.

73. Bizon, K., Continillo, G., Leistner, K., Mancaruso, E. et al., "POD-based analysis of cycle-to-cycle variations in an optically accessible diesel engine," P. Combust. Inst. 32(2): 2809-2816, 2009.

74. Chen, H., Hung, D., Xu, M., Zhuang, H. et al., "Proper orthogonal decomposition analysis of fuel spray structure variation in a spark-ignition direct-injection optical engine," Exp Fluids 55: 1703, 2014.

75. Sirovich, L., "Turbulence and dynamics of coherent structures Part I: coherent structures," Q. Appl. Math. 45(3): 561-571, 1987.

76. Sandford, M., Page, G. and Crawford, P., "The All New AJV8," SAE Technical Paper 2009-01-1060, 2009.

77. Hollander, M., Wolfe, D. and Chicken, E., Nonparametric Statistical Methods (third edition), New Jersey: John Wiley \& Sons, 2014. 
78. Liu, K. and Haworth, D., "Development and Assessment of POD for Analysis of Turbulent Flow in Piston Engines," SAE Technical Paper 2011-01-0830, 2011.

79. Stone, R., Zhao, H. and Zhou, L., "Analysis of Combustion and Particulate Emissions when Hydrogen is Aspirated into a Gasoline Direct Injection Engine," SAE Technical Paper 201001-0580, 2010.

80. Ball, J., Stone, R. and Raine, R., "A Technique for Estimating Completeness of Combustion and its Use in Modeling CycleBy-Cycle Variations in Combustion," SAE Technical Paper 2000-01-0953, 2000.

81. Shen, L., Teh, K., Ge, P., Wang, Y. et al., "Detecting outliers in crank angle resolved engine flow field datasets for proper orthogonal decomposition," SAE Technical Paper 2017-010612, 2017.

82. Gao, R., Shen, L., Teh, K., Ge, P. et al., "Effects of outlier flow field on the characteristics of in-cylinder coherent structure identified by POD-based conditional averaging and quadruple POD," ASME ICEF Paper 2018-9561, 2018.

\section{Contact Information}

\section{Richard Stone}

Engineering Science, Parks Road, OX1 3PJ

richard.stone@eng.ox.ac.uk

\section{Definitions/Abbreviations}

\begin{tabular}{|l|l|}
\hline${ }^{\circ} \mathrm{CA}$ & Crank angle degrees \\
\hline aTDC & After top dead centre \\
\hline bTDC & Before top dead centre \\
\hline DISI & Direct injection spark ignition \\
\hline EVC/EVO & Exhaust valve closed/open \\
\hline FWHM & Full width half maximum \\
\hline GDI & Gasoline direct injection \\
\hline IC & Internal combustion \\
\hline IMEP & Indicated mean effective pressure \\
\hline IVC/IVO & Inlet valve closed/open \\
\hline LIGS & Laser-induced grating spectroscopy \\
\hline MFB & Mass fraction burnt \\
\hline PFI & Plenum fuel injection \\
\hline POD & Proper orthogonal decomposition \\
\hline PLIF & Planar laser induced fluorescence \\
\hline RI & Relevance Index \\
\hline TC-PLIF & $\begin{array}{l}\text { Two-colour planar laser induced } \\
\text { fluorescence }\end{array}$ \\
\hline TDC & Top dead centre \\
\hline
\end{tabular}

\section{Appendix - Performing POD using SVD}

First, the fluctuating temperature data is organised into a column-wise data matrix $\widehat{T}$, where the row entries refer to grid points:

$$
\widehat{T}=\left[\begin{array}{cccccc}
\mid & \mid & \mid & \mid & \mid & \mid \\
\hat{T}_{1} & \widehat{T}_{2} & \cdots & \hat{T}_{n} & \cdots & \hat{T}_{N} \\
\mid & \mid & \mid & \mid & \mid & \mid
\end{array}\right] .
$$

The SVD yields one $M$-rank diagonal singular value matrix $\Sigma$ (whose values are sorted in descending order, $\sigma_{1} \geq \sigma_{2} \geq \cdots \geq \sigma_{M}$ ) and two unitary matrices $U$ and $V$, such that $\widehat{T}=U \Sigma V^{\prime}{ }^{3}$ The first $M$ columns of the left unitary matrix $U$ are the POD modes $\left(\operatorname{denote} \phi^{(m)}, m=1,2, \ldots, M\right.$ and $M \leq$ $N)$ :

$$
\phi=\left[\begin{array}{cccccc}
\mid & \mid & \mid & \mid & \mid & \mid \\
\phi^{(1)} & \phi^{(2)} & \cdots & \phi^{(m)} & \cdots & \phi^{(M)} \\
\mid & \mid & \mid & \mid & \mid & \mid
\end{array}\right] .
$$

The corresponding coefficients $C$ can thus be obtained by $C=\phi^{\prime} \hat{T}$, where the row entries are mode numbers and column entries are cycle numbers, i.e.:

$$
C=\left[\begin{array}{cccccc}
C_{1}^{(1)} & C_{2}^{(1)} & \cdots & C_{n}^{(1)} & \cdots & C_{N}^{(1)} \\
C_{1}^{(2)} & C_{2}^{(2)} & \ddots & C_{n}^{(2)} & \ddots & C_{N}^{(2)} \\
\vdots & \ddots & \ddots & \ddots & \ddots & \vdots \\
C_{1}^{(m)} & C_{2}^{(m)} & \ddots & C_{n}^{(m)} & \ddots & C_{N}^{(m)} \\
\vdots & \ddots & \ddots & \ddots & \ddots & \vdots \\
C_{1}^{(M)} & C_{2}^{(M)} & \cdots & C_{n}^{(M)} & \cdots & C_{N}^{(M)}
\end{array}\right]
$$

${ }^{3}$ Here the notation " ' '" denotes matrix transpose. 